to $7.5 \times 10^{6}$ rads $\mathrm{M}^{-1}$ (mean values) were obtained by means of a linear accelerator at the Atomic Energy Research Establishment, Wantage. Degassed samples were irradiated in break-seal tubes. Gaseous products were separated at $-196^{\circ},-80^{\circ}$ and in some cases also at $-120^{\circ} \mathrm{C}$ and analysed by gas chromatography and mass spectrometry. Liquid products were analysed by gas chromatography, infra-red and ultra-violet spectroscopy, and chemical methods (Table 1). The solid residue left after low-temperature distillation was analysed chemically and by ultra-violet absorption spectroscopy in solution.

The production of water in the case of nitromethane was shown by the Carl Fischer reagent and the solid residue was found to contain the cis dimer of nitrosomethane. It is possible that the trans form could have boen earried over with substrate during distillation, but this was not substantiated.

Some of the products quoted were a result of reactions occurring a considerable time after the initial irradiation. The yield of gaseous products from irradiated nitromethane was drastically reduced if after a short irradiation, such as that obtainod by using a linear accelerator, the samples wero immediately quenched in liquid nitrogen until analy. sis. Under these conditions $G\left(\mathrm{~N}_{2}\right), 0 \cdot 19 ; G(\mathrm{CO}), 0 \cdot 27$; $G(\mathrm{NO}), 0.38 ; G\left(\mathrm{CH}_{4}\right), 0.08 ; G\left(\mathrm{H}_{2}\right), 0.21 ; G\left(\mathrm{CO}_{2}\right), 0.31$; $G\left(\mathrm{~N}_{2} \mathrm{O}\right), 0 \cdot 35 ; G\left(\mathrm{CH}_{3} \mathrm{ONO}\right), 1 \cdot 58 ; G\left(\mathrm{C}_{2} \mathrm{H}_{6}\right), 0 \cdot 09 ; G(\mathrm{HCHO})$, $0.32 ; G\left(c i s-\left(\mathrm{CH}_{3} \mathrm{NO}\right)_{2}\right), 0.43$. It was noted that the decrease in gaseous products was accompanied by an increase in the yield of cis-nitrosomethane dimer. Allowing the sample to stand at room temperature for varying lengths of time increased the yields of nitrogen, carbon monoxide, carbon dioxide and nitrous oxide up to the limiting values quoted in Table 1 . The post-irradiation reaction effects were complete after $5 \mathrm{~h}$ at room temperature.

The addition of iodine as a radical scavenger had no detectable effect on the amount of gaseous products. Nitrous oxide, a potential electron scavenger, slightly increased the nitrogen and carbon monoxide yields.

Table 1. Products Found (APPROXIMATE VALUES)

(1) From nitromethane, $G\left(\mathrm{~N}_{2}\right), 0 \cdot 86 ; G(\mathrm{CO}), 0 \cdot 39 ; G(\mathrm{NO}), 0 \cdot 34 ; G\left(\mathrm{CH}_{4}\right)$,

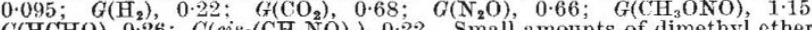
$G(\mathrm{HCH})$, $0 \cdot 26 ;$;
methyl nitrite, formaldoxime, water and methanol were also detected.

(2) From nitroethane, $G\left(\mathrm{~N}_{2}\right), 0.50 ; G(\mathrm{CO}), 0.094 ; G(\mathrm{NO}), 0.08 ; G\left(\mathrm{CH}_{4}\right)$, $0.02 ; G\left(\mathrm{H}_{2}\right), 0 \cdot 08 ; G\left(\mathrm{CO}_{2}\right), 0 \cdot 12 ; G\left(\mathrm{~N}_{2} \mathrm{O}\right), 0 \cdot 73 ; G\left(\mathrm{C}_{2} \mathrm{H}_{4}\right), 0 \cdot 78 ; G\left(\mathrm{C}_{2} \mathrm{H}_{6}\right)$, $0 \cdot 18$. Ethyl nitrite and acetaldehyde were also detected.

(3) From 1-nitropropane, $G\left(\mathrm{~N}_{2}\right), 0.74 ; G(\mathrm{CO}), 0.08 ; G(\mathrm{NO}), 0.35 ; G\left(\mathrm{CH}_{4}\right)$, $0.02 ; \quad G\left(\mathrm{H}_{2}\right), 0.02 ; G\left(\mathrm{CO}_{2}\right), 0.31 ; G\left(\mathrm{~N}_{2} \mathrm{O}\right), 0.71 ; G\left(\mathrm{C}_{3} \mathrm{H}_{5}\right), 0.54 ; G\left(\mathrm{C}_{2} \mathrm{H}_{6}\right)$, (4) From 2-nitropropane, $G\left(\mathrm{~N}_{2}\right), 1.48 ; G(\mathrm{CO}), 0.04 ; G(\mathrm{NO}), 0.21$;

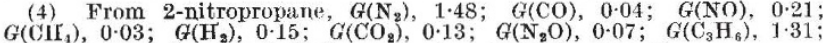

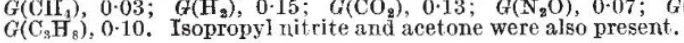

An examination of the decomposition of pure nitromethane was made by the technique of pulse radiolysis using the apparatus developed by Dr. J. P. Keene of the Christio Hospital and Holt Radium Institute, Manchester ${ }^{3}$. Two absorbing species were found, the spectra of which showed an absorption which increased from $6000 \AA$ as the absorbing wave-longth decreased. One of the species decayed by a second-order process, the other seemed to be relatively stable and increased with increasing dose rate and ropeated pulsing. The identity of these species has not been definitely established, but it is tentatively suggested that the long-lived material is monomeric nitrosomethane and the shorter lived species is $\mathrm{CH}_{2} \mathrm{NO}_{2}$ which is removed by a bimolecular acid-base reaction. Owing to the acidic nature of the solvent, the lifetime of tho analogue of the hydrated electron in an aqueous modium would bo very short-lived.

No simple schemo is capable of explaining the observations and it is not possible to discuss adequately the mechanism here. The nature of the products can be explained in terms of a free radical scheme involving initial production of an alkyl radical and nitrogen dioxide such as that advanced for the photolysis of nitromethane ${ }^{4}$. This is certainly an oversimplification and it is significant that the proportions of products vary in the photochemical and radiation systems. For example, the low yields of paraffins suggest that primary processes other than homolytic fission are important. Ionic processes which occur in the mass spectrometer ${ }^{5}$ are feasible in the radiolysis of nitromethane; in particular:

$$
\begin{aligned}
\mathrm{CH}_{3} \mathrm{NO}_{:}^{+} & \rightarrow \mathrm{CH}_{3} \mathrm{O}+\mathrm{NO}^{+} \\
& \rightarrow \mathrm{CH}_{3}^{+}+\mathrm{NO}_{2} \\
& \rightarrow \mathrm{CH}_{3}+\mathrm{NO}_{2}^{+}
\end{aligned}
$$

Other reactions possible are:

$$
\begin{aligned}
\mathrm{CH}_{3} \mathrm{NO}_{2}^{-} & \rightarrow \mathrm{CH}_{3}+\mathrm{NO}_{2}^{-} \\
& \rightarrow \mathrm{CH}_{3}^{-}+\mathrm{NO}_{2} \\
& \rightarrow \mathrm{CH}_{3} \mathrm{NO}+\mathrm{O}^{-} \\
& \rightarrow \mathrm{CH}_{3} \mathrm{NO}^{-}+\mathrm{O}
\end{aligned}
$$

Certainly all the products found can be explained in terms of reactions involving these intermediates.

We thank Dr. J. P. Keene and Mr. K. Melhuish for assistance, the Atomic Energy Research Establishment, Wantage, for use of facilities, and the U.K.A.E.A. for support.

R. B. Cundall

A. W. LOCKE

G. C. Street

Department of Chemistry,

University of Nottingham.

1 Paszyc, S., Photochemistry and Photobiology, 4, 841 (1965).

a Asmus, K. D., Henglein, A., Ebert, M., and Keene, J. P., Ber. Bunsenges. physik. Chemie, 68, 657 (1964), and references quoted therein.

Keene, J. P., J. Sei. Instrum., 41, 493 (1964)

- Rebbert, R. E., and Slagg, N., Bull. Soc. Chim. Belg., r1, 709 (1962).

Collin, J., Bull. Soc. Roy. Sci. Liège, 23, 194 (1954). Kandel, R. J., J. Chem. Phys., 23, 84 (1955). Aldrich, J. H., Cundall, R. B., and Palmer, T. F. (to be published)

\section{Improvements in Sensitivities with Flame Ionization Detectors}

Communications following our letter "Safety in Air Separation Plants-Determination of Atmospheric Pollutants by Gas Chromatography" have indicated that $\operatorname{som} \theta$ difficulty has been found in obtaining the quoted sensitivitios. In order to obtain these detection levels, certain precautions are necessary which are not commonly adopted when using flame ionization detectors.

The use of oxygen in place of the more widely used air for combustion purposes provides about a five- to ten-fold incrcase in sensitivity, but of at least equal importance is the carrior and combustion gas purity. 'The carrier gas used throughout our experiments was holium, purified by the titanium-hopealite-molecular sieve train described by Berry ${ }^{2}$, but it should be noted that less expensive argon may be similarly purified. The combustion gases wero passed through $12 \mathrm{ft}$. $(\times 0 \cdot 25$ in. o.d.) columns of Davison's silica gel, re-activated at regular intervals. The in situ generation of electrolytic hydrogen would be a preferred mothod $^{3}$. Finally, the signal co-axial connecting cable between the detector and amplifier must be kept scrupulously clean, with all insulators having a resistance in excess of $100 \mathrm{M} . \mathrm{ohm}$. In the present case it was found necessary to clean the signal cable thoroughly every $24 \mathrm{~h}$.

We believe that a more rigorous purification of the combustion gases, in conjunction with improved precautions in order to maintain a high insulation, will improve sensitivity lovels even further.

Petrocarbon Developments, Ltd.,

K. Jones

R. GReEN Sunlight House,

Quay St., Manchester.

${ }^{1}$ Jones, K., and Green, R., Nature, 205, 67 (1965).

'Berry, R., Intern. Symp. Gas Chromatog. (Hamburg, 1962). "Hydrogen Generator, Wilkins Instruments and Research, civic Centre,
Hale Top, Wythenshawe, Manchester. 